\title{
Análise de fácies e petrografia de uma seção do Membro Crato em Nova Olinda (CE): contribuições à história deposicional e diagenética do neoaptiano na Bacia do Araripe
}

\author{
Facies analysis and petrography of a section of the Crato Member in Nova Olinda (CE): \\ contributions to the depositional and diagenetic history of the Late Aptian in the \\ Araripe Basin \\ Felipe Holanda dos Santos ${ }^{1,2}$, Juan Moreira de Azevedo², Daniel Rodrigues do Nascimento Junior ${ }^{2}$, \\ Ana Clara Braga de Souza ${ }^{3}$, Marcio Mendes $^{2}$, Irineudo Bezerra² e Saulo Limaverde ${ }^{3}$ \\ Universidade Estadual de Campinas - UNICAMP, Instituto de Geociências, Rua João Pandiá Calógeras, 51, CP 6152, \\ CEP 13083-970, Campinas, SP, Brasil (felipeholanda@ige.unicamp.br) \\ 2Universidade Federal do Ceará - UFC, Departamento de Geologia, Fortaleza, CE, Brasil (juan.mdeazevedo@hotmail.com; \\ daniel.rodrigues@ufc.br; paleonto@ufc.br; irineudobezerra@yahoo.com.br) \\ ${ }^{3}$ Universidade Federal do Ceará - UFC, Departamento de Geologia, Programa de Pós-graduação em Geologia, Fortaleza, \\ CE, Brasil (anaclarageologia@alu.ufc.br; saulolimaverde@yahoo.com.br)
}

Recebido em 16 de agosto de 2015; aceito em 28 de junho de 2016

\begin{abstract}
Resumo
Na Bacia do Araripe, o Membro Crato é uma das mais importantes unidades estratigráficas por seu conteúdo fossilífero, seu contexto análogo ao das "Camadas Pré-Sal" e seu aproveitamento econômico como material de revestimento. Neste trabalho, análises de fácies e petrográficas foram combinadas no estudo de uma seção do Membro Crato em Nova Olinda (CE), com o intuito de investigar sua história deposicional e diagenética. Para tanto, a faciologia de uma seção colunar contínua de cerca de $70 \mathrm{~m}$ de espessura foi analisada com a coleta de 13 amostras de rochas carbonáticas, siliciclásticas e evaporíticas. As amostras foram analisadas por petrografia ótica. Foram descritas cinco fácies deposicionais: lamito margoso $(\mathrm{Lm})$, calcilutito laminado $(\mathrm{Cl})$, arenito maciço $(\mathrm{Am})$, siltito com laminação cruzada cavalgante (Scc) e evaporito colunar (Ec). As fácies mais espessas e recorrentes foram interpretadas como lacustres ( $\mathrm{Lm}, \mathrm{Cl}$ ), seguidas de sucessões aluviais (Am, $\mathrm{Scc}$ ) em meio aos intervalos lacustres. A sucessão termina com indícios faciológicos de que condições de extrema aridez (Ec) foram atingidas ao final do intervalo descrito. A petrografia, aqui focada em rochas das fácies $\mathrm{Cl}$, Am e Scc, reforça a ideia de que o intervalo do Aptiano local correspondia a um sistema lacustre árido, eventualmente alimentado por fluxos aluviais imaturos a partir de áreas-fontes próximas. Em particular, o baixíssimo grau de compactação mecânica e cimentação incipiente das rochas terrígenas sugere que a sucessão foi pouco afetada por diagênese após seu soterramento, que foi, por essa razão, pouco profundo. A semelhança dos intervalos terrígenos do Membro Crato com aqueles descritos para a porção final da sotoposta Formação Barbalha sugere contemporaneidade com passagem transicional retrogradante entre as duas unidades.
\end{abstract}

Palavras-chave: Bacia do Araripe; Membro Crato; Análise de fácies; Diagênese.

\begin{abstract}
The Crato Member is one of the most important stratigraphic units of the Araripe Basin due to its fossil content, its context analogous to the Brazilian "Pre-Salt Layers", and its use as covering stone. Facies and petrographic analyses were combined in our study of a section of the Crato Member in Nova Olinda (State of Ceará, Brazil), aiming to investigate its depositional and diagenetic history. Thus, we analysed the faciology of a continuous columnar section ca. $70 \mathrm{~m}$ thick, and collected 13 samples of limestones, sandstones and evaporites. The collected samples were analysed by optical petrography. Five depositional facies were described: massive marly mudstone $(\mathrm{Lm})$, laminated calcilutite $(\mathrm{Cl})$, almost-massive arenite (Am), siltite with climbing ripple lamination $(\mathrm{Scc})$, and columnar evaporite $(\mathrm{Ec})$. The thickest and recurrent facies were interpreted as lacustrine ( $\mathrm{Lm}, \mathrm{Cl}$ ), followed by alluvial successions (Am, Scc) interbedded between the lacustrine ones. The succession finishes with faciological evidences for extreme arid conditions $(\mathrm{Ec})$ reached at the end of the interval. The petrography, here focused on rocks of facies $\mathrm{Cl}$, Aqm, and Scc, reinforces the idea of an arid lacustrine system for the local Aptian Stage,
\end{abstract}


and that this system was fed by immature alluvial flows coming from close source areas. Particularly, the very low grade of mechanical compaction and incipient cementation of the terrigenous rocks suggest that the succession as a whole was barely affected by diagenesis after burial that, for this reason, was shallow. The resemblance of the Crato Member terrigenous intervals to the ones of the final of the underlying Barbalha Formation suggests contemporaneity and transitional retrograding passage from one unit to another.

Keywords: Araripe Basin; Crato Member; Facies analysis; Diagenesis.

\section{INTRODUÇÃO}

Na Região Nordeste, o Membro Crato (Formação Santana) talvez seja a unidade litoestratigráfica mais importante da Bacia do Araripe, representada por depósitos do intervalo final do Aptiano ou em parte do Andar Alagoas local (Regali e Viana, 1989). Historicamente, a grande atenção dada à unidade se deve ao seu rico conteúdo fossilífero, inestimável para a compreensão do Período Cretáceo das bacias brasileiras e africanas (Mabesoone e Tinoco, 1973; Assine, 2007). Nos últimos anos, o Membro Crato tem chamado atenção para estudos voltados à geologia do petróleo, por também abranger o intervalo equivalente ao do chamado "Pré-Sal" das bacias de margem costeira do Brasil, o que o coloca em situação de análogo potencial para modelagem de reservatórios das bacias produtoras. Localmente, no entanto, seu aproveitamento econômico tem-se limitado ao uso como material de revestimento ("Pedra Cariri") em pisos, paredes etc. (Brasil, 2014). Por esse motivo, trabalhos no Aptiano da Bacia do Araripe, voltados a geometria dos depósitos, relações estratigráficas e diagênese, como os de Neumann (1999), Castro et al. (2006), Chagas et al. (2007) e Freitas (2010), têm fornecido dados valiosos. Entretanto, algumas questões permanecem controversas, como o modo de transição entre as formações Barbalha (sotoposta) e Santana (Silva, 1986; Assine, 1992; Neumann, 1999; Assine, 2007) e a história de soterramento da bacia nesse intervalo de tempo (Silva, 1988; Neumann, 1999; Costa et al., 2014).

O estudo de processos deposicionais e diagenéticos é a principal tarefa na análise de bacias sedimentares (Allen e Allen, 2006; Weltje e von Eynatten, 2004) e repercute na compreensão das relações estratigráficas e na viabilidade econômica de reservatórios (Tucker e Bathurst, 1990). Em campo, os processos deposicionais são geralmente estudados por análise de fácies, que consiste na descrição e classificação de uma rocha sedimentar, seguida pela interpretação de seus processos e sistemas deposicionais envolvidos, em que os últimos são usualmente representados em termos de modelos de fácies (Anderton, 1985). Por sua vez, os processos diagenéticos representam o conjunto de transformações físicas, químicas e biológicas atuantes em um sedimento após sua deposição (Boggs, 2009), sendo estudados em laboratório com base em amostras coletadas no campo. A diagênese pode ser estudada por uma série de diferentes técnicas, das quais a petrografia por microscopia de luz polarizada é uma das mais básicas. Nesse sentido, o uso da análise de fácies atrelado ao estudo da diagênese constitui-se em ferramenta importante para a análise de bacias sedimentares.

Neste artigo são apresentados resultados de trabalhos de campo e de estudos petrográficos com o objetivo de interpretar as condições sedimentológicas de deposição (singenéticas) e soterramento (diagenéticas) em uma seção geológica do Membro Crato aflorante no município de Nova Olinda (CE).

\section{MATERIAIS E MÉTODOS}

A área de estudo situa-se cerca de $4 \mathrm{~km}$ a leste da localidade de Araporanga, no município de Nova Olinda, CE (Figura 1B). Ali, rochas do Membro Crato foram examinadas por critérios de análise faciológica (Selley, 1970; Anderton, 1985; Walker, 1992) em uma seção contínua de aproximadamente $70 \mathrm{~m}$ de espessura, alongada por cerca de $2.690 \mathrm{~m}$ na orientação aproximada $\mathrm{N}-\mathrm{S}$, desde as proximidades de um morro-testemunho do embasamento cristalino local (Morro do Massapê), na base (cota $521 \mathrm{~m}$ ), até o primeiro nível de evaporitos (Camadas Ipubi), no topo (cota $583 \mathrm{~m}$ ). Foram coletadas 13 amostras (seis de calcários e sete de arenitos) para análise petrográfica com microscópio de luz polarizada. As análises seguiram critérios texturais e mineralógicos convencionais de descrição e interpretação de calcários (Folk, 1962; Dunham, 1962; Choquette e Pray, 1970; Logan et al., 1969; Wilson, 1975) e arenitos (Dott Junior, 1964; Griffiths, 1967; Folk, 1968, 1974; Dickinson, 1970; Pettijohn et al., 1987; Schmidt et al., 1977; Nichols, 2009).

\section{CONTEXTO GEOLÓGICO REGIONAL}

A Bacia do Araripe enquadra-se no contexto das bacias interiores do Nordeste do Brasil e, dentre estas, destaca-se como a mais representativa das exposições de rochas cretáceas (Carvalho e Bertini, 1999; Figura 1A). A bacia teria se formado a partir de eventos tectônicos responsáveis pela fragmentação do paleocontinente Gondwana e abertura do oceano Atlântico Sul (Matos, 1992). A abertura desse oceano, em particular, seria responsável pela formação dos riftes mesozoicos do Nordeste do Brasil, cuja arquitetura deposicional é hoje representada por uma série de blocos falhados, na forma de grábens e horsts recobertos por depósitos sedimentares de idade Aptiano-Albiano (Ponte e Ponte-Filho, 1996). 


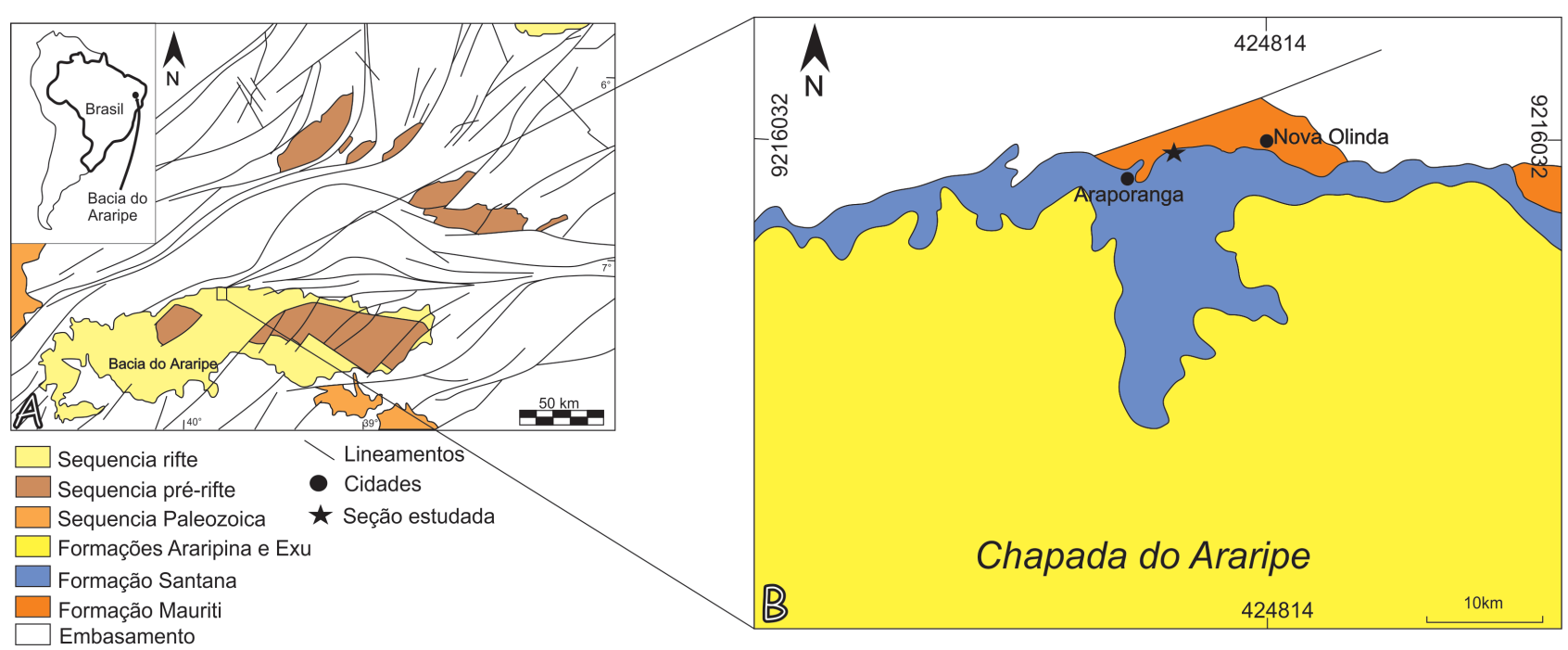

Figura 1. (A) Mapa geológico dos riftes interiores do Nordeste do Brasil (modificado de Matos, 1992). (B) Mapa geológico com localização da seção estudada no município de Nova Olinda (Modificado de Assine, 2007).

Das diversas subdivisões litoestratigráficas propostas para a Bacia do Araripe, destacam-se as descritas por Ponte et al. (1991), Ponte et al. (1997) e Assine (2007). Na Bacia do Araripe, Assine (2007) reconheceu cinco sequências deposicionais limitadas no topo e na base por discordâncias de caráter regional: (1) "Sequência Paleozoica", representada pela Formação Mauriti; (2) "Sequência pré-rifte" (Neojurássica), correspondente às Formações Brejo Santo e Missão Velha; (3) "Sequência rifte", equivalente à Formação Abaiara; (4) "Sequência Pós-rifte I" (Aptiano-Albiano), correspondente às Formações Barbalha e Santana; (5) "Sequência Pós-rifte II", equivalente às Formações Araripina e Exu (Figura 2).

A sucessão analisada no presente estudo compreende a maior parte do Membro Crato, unidade basal da Formação Santana, e possui uma espessura estimada em cerca de 80 m (poço 2-AP-1-CE; Assine, 2007). Assine (2007) subdivide a Formação Santana em dois membros: o Membro Crato, constituído predominantemente por calcilutitos de cor creme-amarelada, bem estruturados com laminações plano-paralelas e peixes fósseis do gênero Dastilbe, e o Membro Romualdo, constituído por pelitos, margas e calcários, em parte representativo de uma transgressão marinha sobre sistemas lacustres antecedentes. Entre os dois membros, ocorrem as chamadas Camadas Ipubi (Assine, 2007), caracterizadas pela ocorrência descontínua de gipsita e anidrita em áreas localizadas, sendo possíveis representantes de pequenas bacias marginais ou salinas tipo sabkha playa; as camadas Ipubi marcariam o intervalo final do Membro Crato.

A "Sequência Pós-rifte I" (Ponte e Ponte-Filho, 1996; Assine, 2007), dentro da qual a Formação Santana se enquadra, abrange o intervalo da bacia que registraria um ciclo deposicional quase completo, regressivo-transgressivo, sendo limitada na base por uma discordância pré-aptiana que a separa de sucessões mais antigas e/ou do embasamento. Nesse contexto, a Formação Santana (Aptiano/Albiano) localiza-se logo acima do início do chamado "último ciclo fluvial granodecrescente" da Formação Barbalha (Assine, 2007). A Formação Barbalha, base da Sequência Pós-rifte I, inicia-se com conglomerados e bancos espessos de arenitos médios, culminando em folhelhos cinza-escuro, verdes e vermelhos, calcíferos, laminados, que ocorrem imediatamente sotopostos aos calcilutitos do Membro Crato (Chagas et al., 2007).

\section{RESULTADOS}

\section{Análise de fácies}

\section{Lamito margoso ( $\mathrm{Lm})$}

Esta fácies consiste em lamitos bastante friáveis, pulverulentos, com tons esverdeados (raramente avermelhados) e calcíferos (Figura 3A). Ocorrem como corpos métricos a decamétricos de geometria tabular e internamente laminados (milimetricamente) com textura físsil apenas eventualmente reconhecível. A fácies Lm é a mais comum das fácies descritas, cuja recorrência por toda a seção estudada a faz intercalar-se com todas as demais fácies. Próximo ao topo $(575 \mathrm{~m}) \mathrm{da}$ seção, a fácies $\mathrm{Lm}$ exibe concreções carbonáticas $\left(\mathrm{CaCO}_{3}\right)$ esparsas, com formas oblatas e dimensões até decimétricas (Figura 3B). O topo dessa última recorrência é marcado pela ocorrência de camadas evaporíticas (fácies Ec).

A origem de lamitos maciços da fácies $\mathrm{Lm}$ é aqui admitida como produto de decantação passiva em fundo 


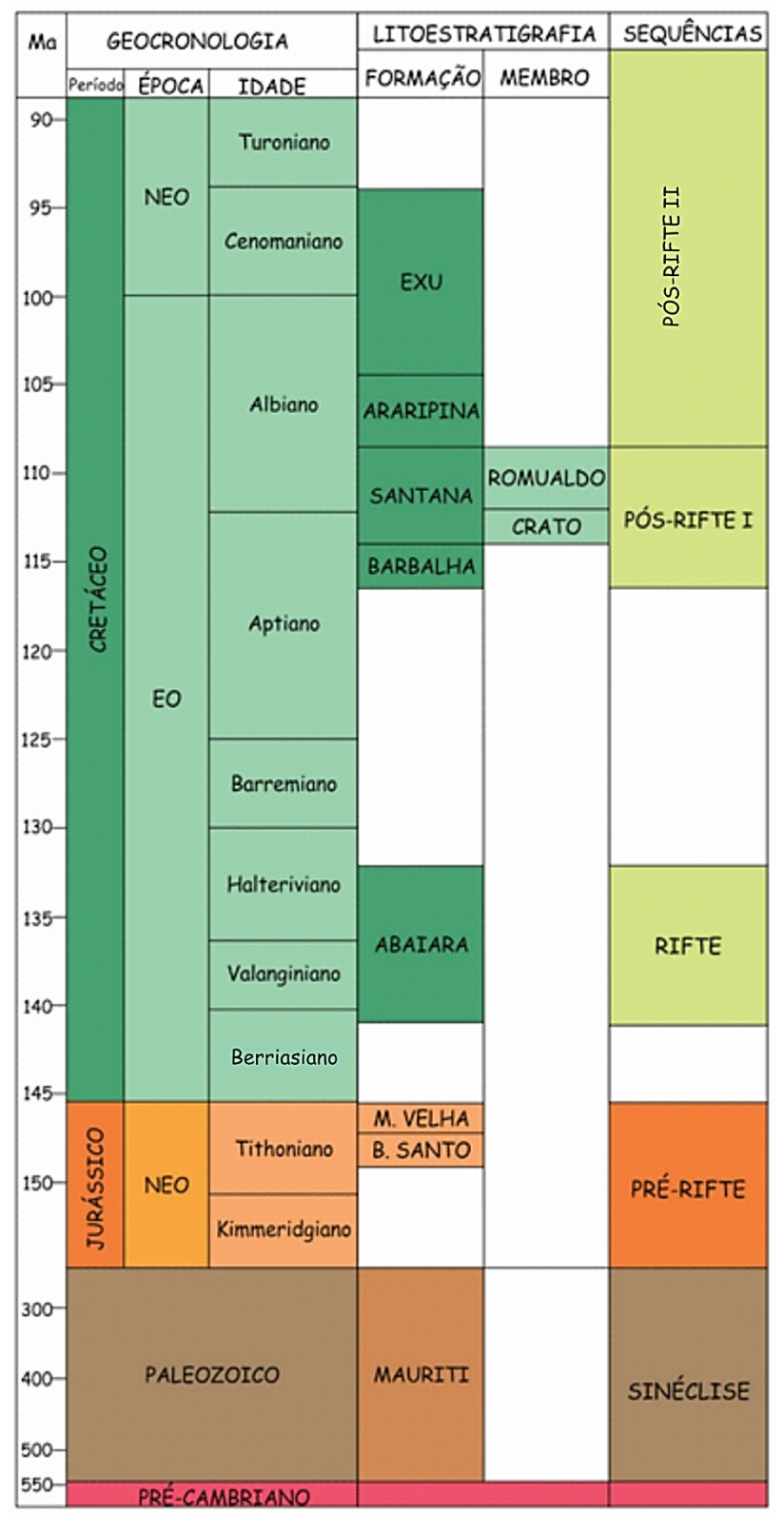

Figura 2. Carta cronoestratigráfica simplificada da Bacia do Araripe (Assine, 2007).

lacustre sob condições alcalinas e predominantemente redutoras. As condições redutoras aqui aventadas se baseiam na coloração geralmente escura (verde) da rocha, aqui interpretada como cor primária; neste caso, tais condições seriam favorecidas por eutrofização do que propriamente por profundidade (lagos euxínicos?). Por esse motivo, a carência de fissilidade nos lamitos da fácies Lm seria atribuída a porções mais siltosas, a alteração rasa em perfis de solo ou mesmo ao caráter margoso da rocha (Alling, 1945), mas não a níveis elevados de oxigenação (Moon e Hurst, 1984). Corrobora para isso a presença de concreções carbonáticas nas proximidades do topo da fácies, o que sugere origem semelhante à aventada para estruturas do mesmo tipo no Membro Romualdo: mineralização eodiagenética favorecida por ação de bactérias redutoras concentradas ao redor de matéria orgânica morta (Fara et al., 2005). No entanto, não foram encontrados fósseis associados às concreções durante essa campanha de estudo.

\section{Calcilutito laminado (Cl)}

A fácies $\mathrm{Cl}$ é formada por calcários finos milimetricamente laminados, compactos e com cor geralmente bege a amarelo-claro (chegando a marrom quando em perfil de alteração de solo). Sua geometria externa é tabular de espessura decimétrica a métrica, onde aparece intercalado em contatos gradacionais com lamitos (fácies Lm) e arenitos; nesse último caso, grãos placoides de mica são abundantes quando a fácies $\mathrm{Cl}$ é a sobreposta. Sua laminação plano-paralela é por vezes acompanhada de fenestras milimétricas alinhadas (Figura 3C). Mais raramente, aparecem estruturas decimétricas de escorregamentos e/ou deslizamentos (micro-slumps, slides; Figura 3D), acamamento convoluto (Figuras 3E e 4), concreções carbonáticas (centimétricas, ovais) e pseudomorfos centimétricos de halita (hopper crystals; Figura 3F). Um nível decimétrico de cor cinza-azulado ocorre horizontalmente próximo ao topo de uma camada, onde sua dureza elevada e baixa reatividade ao ácido clorídrico sugerem intervalo silicificado. Também ocorre um nível de tom avermelhado atribuído à oxidação ferruginosa (óxi-hidróxidos de Fe e Mn?).

Calcilutitos finamente laminados são aqui interpretados como resultado de condições predominantemente calmas de decantação de lama micrítica em águas alcalinas rasas e oxidantes e de salinidade eventualmente elevada. Tais características são compatíveis com as ocorrências em lagos de regiões sob clima árido (sabkhas). Contudo, a presença de estruturas deformacionais (convoluções, escorregamentos etc.) também aponta para fenômenos eodiagenéticos de perturbação episódica de sedimento mole, talvez ligados a fluxos de massa advindos de áreas-fonte elevadas nas proximidades e/ou à atividade sísmica (Andresen e Bjerrum, 1967). A presença de camadas silicificadas em meio ao calcário estaria ligada à cimentação mesodiagenética profunda (condições de alcalinidade extrema; Bustillo, 2010) ou a fenômenos hidrotermais eodiagenéticos sensu strictu (rasos; Bustillo, 2010; Warren, 2000). No caso da oxidação ferruginosa, esta estaria ligada a processos telodiagenéticos pervasivos de laterização (Assine, 2007).

\section{Arenito maciço (Am)}

Os arenitos desta fácies ocorrem em camadas de espessura decimétrica cuja extensão horizontal aflorante (poucos metros) lhe confere geometria aparentemente tabular. Quando sotoposta, esta fácies exibe contato gradacional bem marcado 

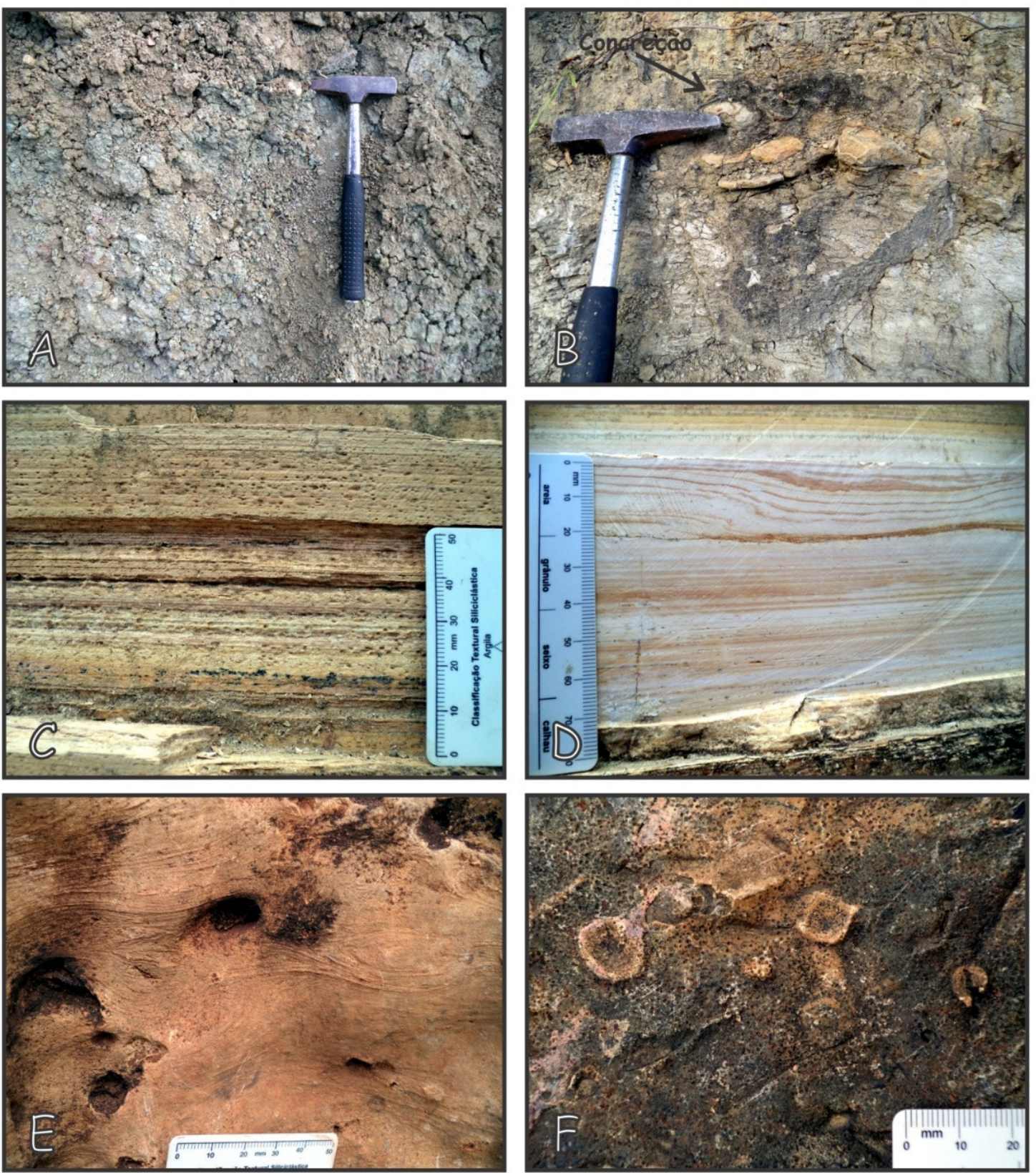

Figura 3. (A) Lamito calcífero verde levemente oxidado (Lm). (B) Contato gradacional entre uma camada de arenito fino com laminação plano-paralela (sotoposta) ao lamito (Lm); na transição entre as camadas, note um nível de concreções. (D) Calcilutito com camadas parcialmente microfalhadas (micro-slumps). (C) Calcilutito com porosidade fenestral alinhada segundo a laminação plano-paralela. (E) Laminação convoluta. (F) Pseudormofo de halita de hábito desenvolvido no calcilutito (visão em corte planar).

com níves decimétricos de calcilutitos, lamitos calcíferos verdes e siltitos (Figura 4). A fácies Am constitui-se em grãos terrígenos desde areia fina até silte grosso $(250$ a $30 \mu \mathrm{m})$, com gradação ligeiramente decrescente para o topo de cada sucessão, em intervalos de cores bege, amarela, cinza e marrom (Figura 5A). Sua reatividade ao ácido clorídrico se deve à cimentação carbonática. A maior parte dos arenitos carece de estruturas internas bem definidas, o que, em parte, pode ser devido a uma escassa segregação granular. Em campo, são visíveis marcas tênues de laminação plano-paralela, às vezes com presença de séries de truncamentos de lâminas ainda mais tênues (tração?). Em um dos arenitos, ocorrem tubos verticais preenchidos por siltito (Figuras 4 e 5B). Os tubos aparecem com seção circular a oval de pelo menos $1 \mathrm{~cm}$ de 

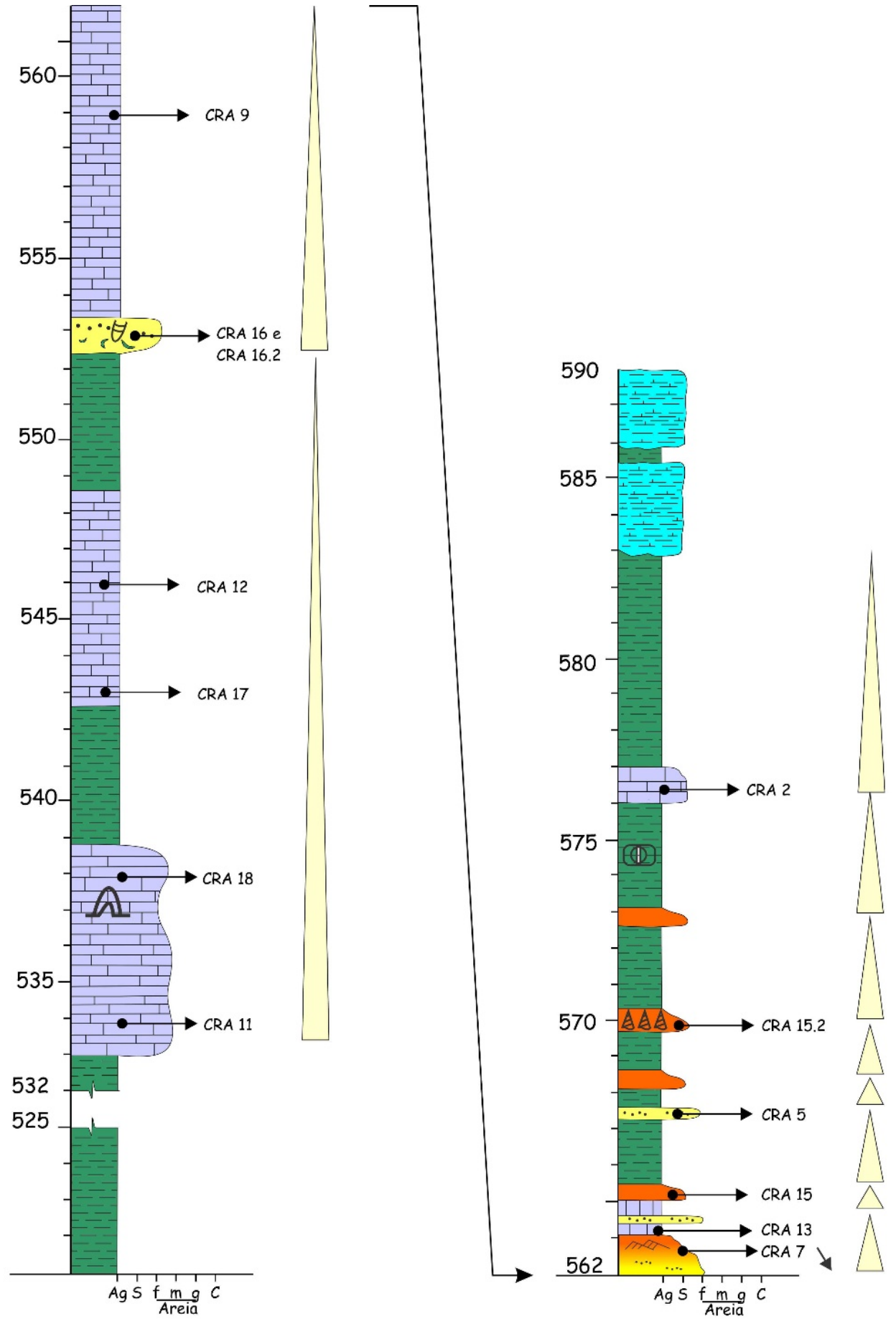

\begin{tabular}{|c|c|c|}
\hline $\begin{array}{l}\text { Fácies deposicionais } \\
-\exists \text { Folhelho margoso }\end{array}$ & $\begin{array}{l}\text { Estr } \\
\text { outr }\end{array}$ & \\
\hline Calcilutito laminado & h Camada convoluta & WES \\
\hline$\cdots$ Arenito quase maciço & $\checkmark$ Intraclastos de lama & Moldes externos de \\
\hline $\begin{array}{l}\text { Siltito com laminação cruzada c } \\
\text { Evaporito colunar }\end{array}$ & $\begin{array}{l}\theta \text { Bioturbação } \\
\forall \text { Paleocorrente } \\
\end{array}$ & $\begin{array}{l}(10 \text { Concreções carbonáticas } \\
\leftrightarrow \text { Lâminas descritas }\end{array}$ \\
\hline
\end{tabular}

Figura 4. Seção colunar em estratos do Membro Crato, na localidade de Araporanga, município de Nova Olinda (CE). 

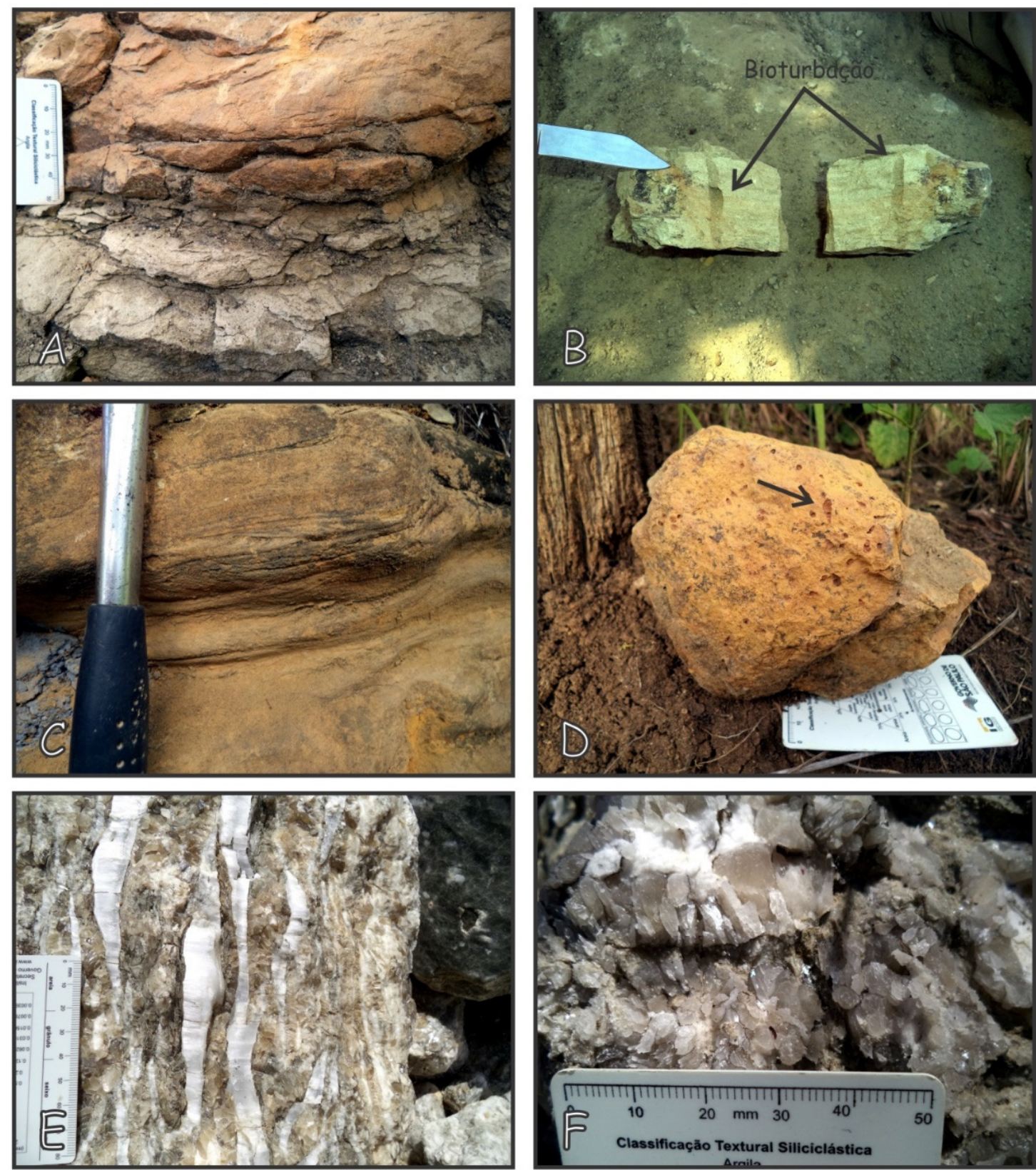

Figura 5. (A) Camada de arenito fino (Am), embaixo na foto, em contato com camada de siltito. (B) Arenito fino com icnitos de bioturbação. (C) Siltito com laminação cruzada cavalgante de fluxo subcrítico (Scc). (D) Moldes de gastrópodes encontrados nos siltitos. (E) Evaporito (Ec) com cristais fibrosos em arranjo sintaxial. (F) Detalhe dos cristais centimétricos de gipsita dispostos em colunas.

diâmetro e extensão vertical ao menos decimétrica, sendo aqui interpretados como icnitos de bioturbação. Decímetros abaixo, no mesmo corpo de arenito, ocorrem intraclastos de lama (lamito calcífero verde) de dimensões centimétricas.

Interpreta-se a fácies Am como resultado de fluxos episódicos de sedimento terrígeno imaturo a partir de áreas-fonte relativamente próximas, com retrabalhamento de parte do sedimento preexistente no leito. A presença de estruturas de bioturbação verticalizadas indica que depósitos recém-chegados eram prontamente colonizados por organismos oportunistas em condições de águas rasas. A interação com águas alcalinas da bacia deve ser responsável pela cimentação carbonática pós-deposicional dos arenitos da fácies Am. Tanto a ausência de boa segregação granular (Pettijohn et al., 1987) como a presença de bioturbação (Moore e Scruton, 1957), combinadas ou não, podem ser responsáveis pela carência de estruturas trativas primárias nesse arenito. 


\section{Siltito com laminação cruzada cavalgante (Scc)}

Os siltitos da fácies Scc ocorrem em camadas decimétricas de geometria tabular, de modo descontínuo e sempre acima dos arenitos (Am), em contato brusco a ligeiramente gradacional. Assim como os arenitos da fácies Am, os siltitos da fácies Scc são cimentados com carbonato de cálcio. Os siltitos interdigitam-se lateralmente com calcilutitos laminados $(\mathrm{Cl})$ e lamitos calcíferos verdes (Lm). Predominam na cor laranja, têm textura lamosa, são compactos e comumente exibem laminação cruzada cavalgante de fluxo subcrítico (Figuras 4 e 5C). O mergulho aproximado das laminações se dirige para os quadrantes meridionais. Em um dos corpos de siltito, aparecem dezenas de contramoldes milimétricos de gastrópodes, vazios a olho nu e em disposição aleatória (Figuras 4 e 5D).

A fácies Scc é interpretada como resultado dos mesmos fluxos episódicos responsáveis pela deposição da fácies Am. Todavia, a granulação mais fina, a presença de laminações cavalgantes e a ocorrência de contramoldes de gastrópodes indicam maior interação dinâmica (durante o fluxo) com as águas da bacia lacustre. No caso particular das laminações, essa interação envolveria alguma carga sedimentar suspensa durante a migração de marcas onduladas, sob condições de turbulência com turbilhonamento (fluxo repentinamente desconfinado; Allen, 1973). As áreas-fonte da fácies Scc (e da fácies Aqm, por extensão) se localizariam a norte da bacia no intervalo de tempo considerado.

\section{Evaporito colunar (Ec)}

Ocorre nas cotas mais elevadas $(570 \mathrm{~m})$ da sucessão, onde exibe contato gradacional com calcilutitos e lamitos sotopostos. No caso mais comum, esse contato é dado por intercalações de camadas decimétricas de lamitos em meio ao evaporito (Figura 4). As lentes/camadas de evaporito afloram na forma de lajedos métricos $(1,8$ por $1,2 \mathrm{~m}$, aproximadamente) e em cortes submétricos de perfil. $\mathrm{O}$ evaporito apresenta-se nas cores branca e cinza, com tenacidade macia, e predominantemente estruturado em colunas ou paliças verticais, feições típicas de cristalização primária de gipsita. Em níveis mais restritos, cristais fibrosos sintaxiais às paliças ou em veios e arranjos fibroradiados (diâmetros de 0,2 a $1 \mathrm{~cm}$ ) também ocorrem como testemunhos de desidratação secundária de gipsita, transformando-se em anidrita (Figuras 5E e F).

Evaporitos colunares são aqui interpretados como produto de precipitação salina de gipsita em águas rasas sob condições de aridez extrema. A intercalação de evaporitos com lamitos, ainda que delgados, sugere flutuações positivas do nível de base lacustre por breves períodos de aporte hídrico (Collinson e Thompson, 1982).

\section{Análise petrográfica}

\section{Fácies Cl}

A petrografia da fácies $\mathrm{Cl}$ apresentou-se bastante monótona, com teor de arcabouço (> $30 \mu \mathrm{m}$ ) desprezível na maioria das lâminas. A fácies é composta de mais de $94 \%$ de matriz na fração microespato e da porcentagem remanescente por cimento. A matriz microespática é pervasiva e composta de cristais de calcita em alternância de níveis mais claros (amarelos) e ligeiramente mais escuros (laranja/ marrons), marcadores da laminação da rocha (Figura 6A). Porções em tons amarronzados, de baixa cristalinidade à luz transmitida e opacas à luz refletida, nos níveis escuros, são interpretadas como enriquecidas em matéria orgânica. O cimento presente é amplamente formado por óxi-hidróxidos de ferro e manganês, de cores marrom-avermelhadas e com hábito dendrítico (Figura $6 \mathrm{~B})$. Subordinadamente $(<1 \%)$, ocorre cimento de composição sulfetada. Ocorre também cimento calcítico espático com hábito poiquilotópico, bem como em crescimento sintaxial do mesmo componente e, mais raramente, como mosaico em drusa. Nesses casos, os cristais de calcita espática preenchem vazios, com consequente redução de sua porosidade primária. Cristais espáticos chegam a alcançar 14\% do total da relação matriz/ cimento (Figura 6C). Localmente, verificaram-se grãos alobioquímicos (bioclastos) na composição do arcabouço ( $1 \%$ na fração) formados por ostracodes com valvas tanto articuladas como desarticuladas, as quais, por vezes, encontram-se neomorfizadas (Figura 6D). Há presença de laminação plano-paralela ligeiramente crenulada (microbial), cimento em menisco e microfalhamentos (Figura 6E). Pelos resultados apresentados, as amostras classificam-se como calcilutitos pseudomicroesparíticos (Folk, 1962) ou mudstones (Dunham, 1962).

\section{Fácies Am}

As rochas da fácies Am apresentam-se texturalmente imaturas (Folk, 1974), com teores de até 55\% de matriz, da qual cerca de $30 \%$ se encontra na forma de ortomatriz, ao passo que a maior parte ocorre na forma de protomatriz (Figura 6F). Em sua maioria, os grãos do arcabouço possuem tamanho de areia muito fina, são moderadamente a bem selecionados, e angulosos a subangulosos. A matriz envolve a maioria dos grãos do arcabouço, que, por sua vez, compõem até $50 \%$ da rocha. Os grãos do arcabouço são mineralogicamente maduros (Pettijohn et al., 1987), compostos predominantemente de quartzo monocristalino (> 90\%) com extinção uniforme. Outros grãos ocorrentes no arcabouço são de mica grossa (aproximadamente 5\%, às vezes amassados), microclínio e fragmentos líticos de quartzo policristalino alongado com extinção ondulante (Figuras $6 \mathrm{G} \mathrm{e} \mathrm{H}$ ). A protomatriz é composta de filossilicatos 


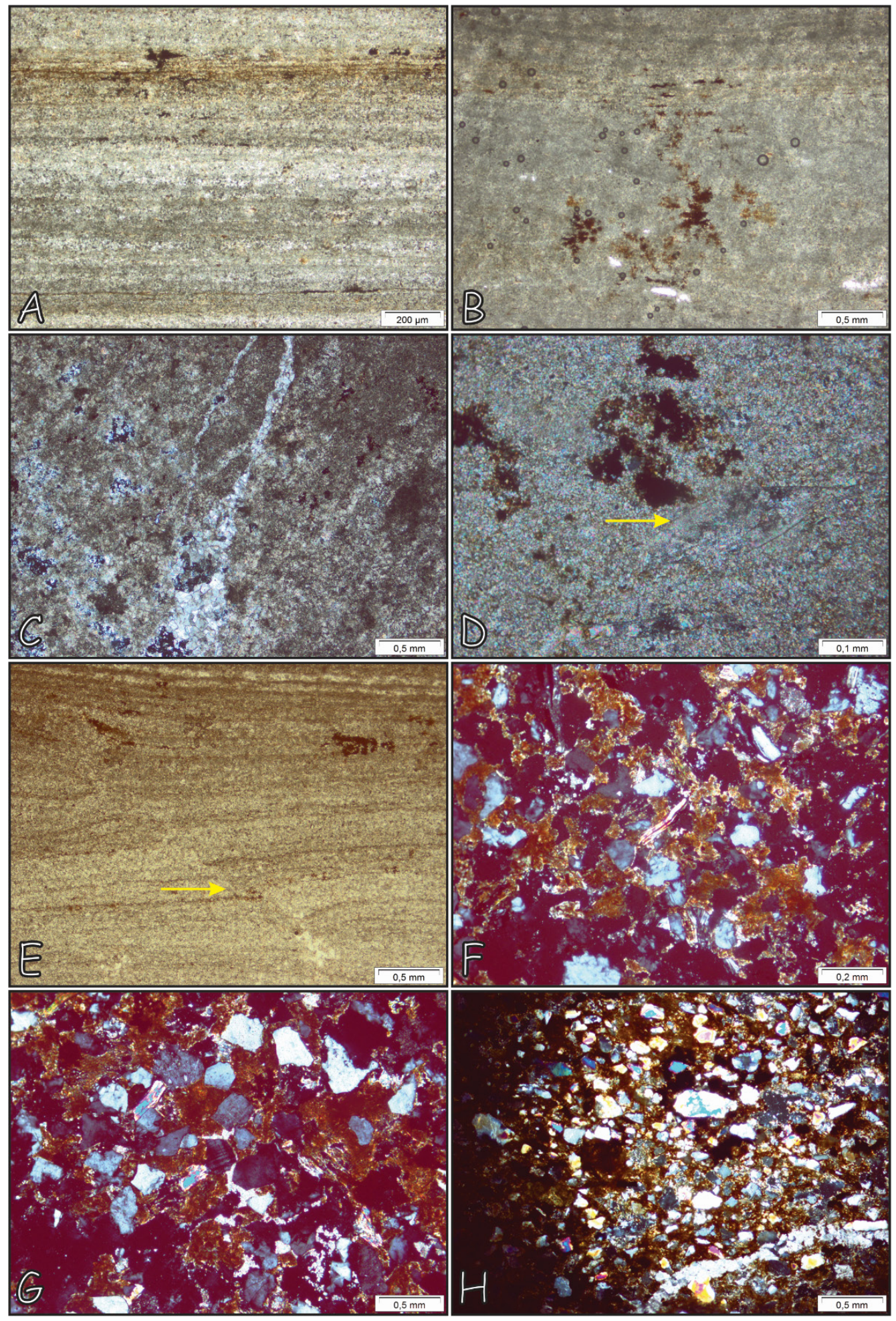

Figura 6. (A) Calcilutito laminado com acamamento levemente ondulado (nicóis paralelos). (B) Calcilutito laminado com níveis ricos em óxi-hidróxido de ferro e manganês (nicóis paralelos). (C) Cimento de calcita espática em preenchimento de fraturas (nicóis cruzados). (D) Valvas articuladas de ostracode indicadas pela seta amarela (nicóis cruzados). (E) Microfalha em calcilutito indicada pela seta amarela (nicóis paralelos). (F) Mica amassada (pseudomatriz) e seta bolsões com acúmulo de protomatriz (nicóis cruzados). (G) Cristais de microclínio com geminação polissintética, mica amassada e quartzo policristalino (nicóis cruzados). (H) Fragmentos líticos de quartzo policristalino (arcabouço) e cimento carbonático em preenchimento de microfratura (nicóis cruzados). 
indistintos, por vezes organizados em agregados irregulares (até milimétricos) de massa microcristalina. Na ortomatriz, os grãos, agora distintos, apresentam tamanho de até dezenas de micrômetros. A petrotrama mostra segregação granular por orientação, composição e tamanho, essa última na forma de gradação normal (Figura 7A). Os grãos dispõem-se predominantemente flutuantes na matriz, o que sugere baixo grau de empacotamento e compactação mecânica apenas incipiente; localmente, aparecem orientados segundo seu maior eixo em corte planar (Figura 7B). Ocorre baixa porosidade primária, às vezes piorada pela presença de mica amassada (pseudomatriz), como um dos raros indícios de algum grau de compactação (Figura 6F). Predominam cimento calcítico $(80 \%)$ e, subordinadamente, óxi-hidróxidos de ferro (até 5\%), argilominerais (10\%) e sulfetos (até 5\%); nesse último caso, a ocorrência é disseminada e em tamanhos

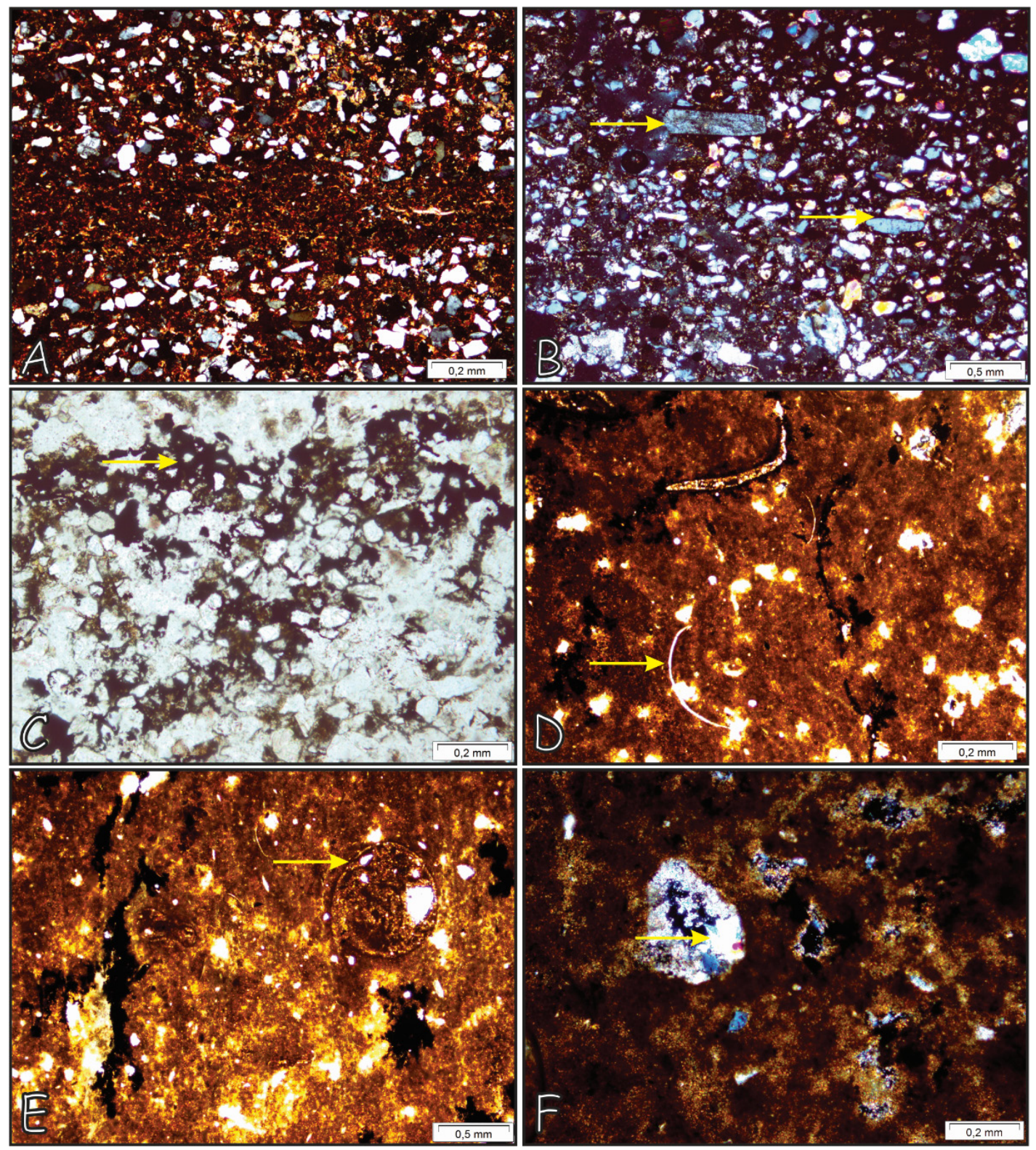

Figura 7. (A) Segregação granular por composição e tamanho, essa última na forma de gradação normal (nicóis cruzados). (B) Grãos moderadamente orientados segundo seu eixo maior (a?), em visão de corte planar (indicação pela seta amarela) (nicóis cruzados). (C) Cimento de óxi-hidróxidos de ferro de baixa cristalinidade e textura tipo grão-envolvente (nicóis paralelos). (D) Seta indicando valva desarticulada de ostracode (nicóis paralelos). (E) Seção radial tênue (ghost) de molde externo de gastrópode (indicado pela seta), quase totalmente preenchido por matriz mecanicamente infiltrada (nicóis paralelos). (F) Porosidade móldica reduzida, com preenchimento de calcita e gipsita (indicados pela seta), em seção longitudinal à concha de gastrópode (nicóis cruzados). 
diminutos $(<50 \mu \mathrm{m})$. A textura do cimento carbonático é principalmente poroenvolvente com distribuição isópaca; menos frequentemente, esse cimento preenche microfraturas (Figura $6 \mathrm{H}$ ). $\mathrm{O}$ cimento de óxi-hidróxidos de ferro apresenta textura na forma de trilhas de agregados microcristalinos que acompanham a laminação. Ali, na maioria dos casos (70\%), apresenta textura poroenvolvente e, em menor frequência, grão-envolvente (Figura $7 \mathrm{C}$ ). As características descritas permitem classificar os arenitos como quartzo-wackes (Dott Junior, 1964).

\section{Fácies Scc}

A matriz da fácies Scc compreende $75 \%$ dos componentes totais, da qual $70 \%$ na forma primária mais fina, indistinta (protomatriz), e $30 \%$ na forma sacaroidal, mais grossa (ortomatriz). Por isso, a fácies é classificada como texturalmente imatura (Folk, 1974). O arcabouço, que compreende 10\% da fácies, também confere imaturidade mineralógica à fácies (Pettijohn et al., 1987), onde se constitui predominantemente por bioclastos ( $>90 \%$ ) com orientação polimodal e frouxamente empacotados; o restante do arcabouço é formado por grãos diminutos de quartzo monocristalino. Os bioclastos são formados de valvas de ostracodes, geralmente desarticuladas (Figura 7D). A maior parte do cimento é composta de óxi-hidróxidos de ferro (65\%) e apresenta texturas do tipo poroenvolvente e preenchimento de poro (Figura 7E). Cimento calcítico ocorre como preenchimento de poros, na maior parte como redutor de porosidade primária do tipo móldica (Figura 7F). Pequenos cristais cimentantes de gipsita ocorrem em um dos poros. A porosidade móldica mencionada é formada por remoção seletiva (dissolução) de bioclastos de ostracodes e, principalmente, de gastrópodes. Esses últimos, em particular, ocorrem exclusivamente como contramoldes externos de alguns milímetros de diâmetro, muito nítidos também em amostras de mão. Características morfológicas do contramolde, como aspecto turriforme em três voltas e abertura ovalada, permitiram a aproximação taxonômica ao nível de família (família Hydrobiidae; Troschel, 1857). As características descritas para as rochas da fácies Scc permitem classificá-las como siltitos (Dott Junior, 1964).

\section{DISCUSSÕES}

\section{Interpretação paleogeográfica}

Na seção estudada do Membro Crato, rochas sedimentares finamente laminadas, como as das fácies $\mathrm{Lm}$ e $\mathrm{Cl}$, implicam sedimentação por decantação sob condições de águas calmas, possivelmente lacustres (Tabela 1). Segundo as relações de contato, aventa-se uma coexistência lateral dessas fácies, entretanto com diferentes condições físico-químicas de deposição. As características texturais e composicionais da fácies $\mathrm{Cl}$ implicam que a deposição ocorreu em condições de águas mais rasas do que as da fácies Lm (ainda que sem evidências de exposição subaérea). A porosidade primária do tipo fenestral sugere deposição dos carbonatos por influência microbiana, o que pressupõe uma superfície de águas rasas e aquecidas do lago. O caráter hipersalino, atribuído à presença de pseudomorfos de halita, corrobora para a interpretação de que sistemas deposicionais rasos eventualmente atingiram condições de clima árido (plataforma evaporítica ou de circulação restrita; Martill et al., 2007). Por outro lado, a deposição de lamitos margosos (fácies Lm) implica espessura maior da lâmina de água, bem como um ambiente alcalino e redutor. A presença de gipsita (fácies Ec) confirma que condições de aridez ocorreram na época da deposição da unidade (Tabela 1). É provável que tenha havido flutuações do nível de base regional por períodos descontínuos de aporte hídrico, haja vista a presença de lamitos (fácies Lm) interdigitados nas camadas evaporíticas. A condição de calmaria da bacia era interrompida pela entrada de corpos terrígenos evidenciados nas fácies Am e Scc (Tabela 1). A fácies Am é interpretada como pertencente

Tabela 1. Sumário das fácies deposicionais descritas para a seção estudada no Membro Crato.

\begin{tabular}{cll}
\hline Fácies & \multicolumn{1}{c}{ Descrição } & \multicolumn{1}{c}{ Interpretação } \\
\hline Lm & $\begin{array}{l}\text { Lamitos em tons esverdeados e/ou avermelhados; } \\
\text { parcialmente constituídos de carbonato de cálcio; textura físsil } \\
\text { eventualmente reconhecível }\end{array}$ & $\begin{array}{l}\text { Decantação de partículas em suspensão sob condições } \\
\text { alcalinas e redutoras }\end{array}$ \\
\hline Cl & $\begin{array}{l}\text { Calcilutitos laminados com tons beges ou amarelados; } \\
\text { contêm pseudomorfos de halita, micro-s/umps, acamamento } \\
\text { convoluto e porosidade fenestral }\end{array}$ & $\begin{array}{l}\text { Decantação de lama carbonática sob condições alcalinas } \\
\text { rasas e oxidantes }\end{array}$ \\
\hline Am & $\begin{array}{l}\text { Arenitos finos com grãos terrígenos desde areia fina até silte } \\
\text { grosso (250 a 30 } \mu \text { m); possuem bioturbações e intraclastos } \\
\text { de lama; contêm tênues laminações plano-paralelas }\end{array}$ & $\begin{array}{l}\text { Sedimentação de fluxos desconfinados, de viscosidade média } \\
\text { a alta }\end{array}$ \\
\hline Scc & $\begin{array}{l}\text { Siltitos cimentados por carbonato de cálcio, compactos, } \\
\text { com textura argilosa, estratificações cruzadas cavalgantes e e } \\
\text { moldes externos de gastrópodes }\end{array}$ & $\begin{array}{l}\text { Sedimentação de fluxos episódicos desconfinados e } \\
\text { hipopicnais }\end{array}$ \\
\hline Ec & $\begin{array}{l}\text { Evaporitos com cristais de dimensões de até 1 cm } \\
\text { estruturados em colunas ou paliças verticais }\end{array}$ & $\begin{array}{l}\text { Precipitação salina de gipsita em águas rasas sob condições } \\
\text { de aridez elevada }\end{array}$ \\
\hline
\end{tabular}


a fluxos desconfinados, de viscosidade média a alta, por seu conteúdo de lama (vista em secção delgada), na forma de leques aluviais. A ocorrência de wackes nessa fácies indica um caráter proximal da área-fonte em relação aos lagos, sobretudo pelo transporte de grãos subangulosos em material lamoso. São, portanto, interpretados como registro da porção terminal (jusante) de antigos leques aluviais dominados por fluxos gravitacionais (gravity flow dominated fans; Blair e McPherson, 1994), que seriam desencadeados por eventos de chuvas intensas sobre áreas elevadas nas proximidades. A presença eventual de intraclastos de flocos de lama (mud flake) permite enquadrar tal fácies como pertencente à margem lacustre. Os depósitos recém-chegados eram rapidamente colonizados por organismos de infauna de águas rasas (tubos de icnofósseis). À medida que os leques aluviais adentravam a bacia, formavam-se leques deltaicos (fandeltas). Os fluxos episódicos responsáveis pela deposição da fácies Am envolveriam carga sedimentar trativa com suspensão associada (laminações cruzadas cavalgantes), em parte pela interação do efluente com as águas da bacia e o fundo. Corrobora para essa interação a presença de associações fossilíferas retrabalhadas, especialmente gastrópodes inteiros e desorganizados da família Hydrobiidae, típicos de águas continentais (Strong et al., 2008). Mais densas, as águas bacinais receberiam o efluente de forma hipopicnal (Bates,
1953), o que pode explicar a segregação de uma parte de seu fluxo, de modo a formar a fácies Scc associada.

\section{Sucessão de eventos diagenéticos}

\section{Eodiagênese}

Indícios de eodiagênese são os mais comuns em todas as fácies anteriormente descritas. Nas rochas carbonáticas da fácies $\mathrm{Cl}$, em um primeiro momento, a eodiagênese é marcada pela presença de laminações crenuladas resultantes de ação microbiana relacionada a fenômenos de decomposição da matéria orgânica, ligada a estruturas fenestrais (Tucker e Bathurst, 1990). Em um segundo momento, a eodiagênese é caracterizada pela presença de cimento sulfetado em meio à massa carbonática, que ocorre apenas localmente, em pequena quantidade, e é interpretado como cimento de primeira geração, sob condições anóxicas de soterramento, possivelmente com atividade bacteriana anaeróbia. A recristalização neomórfica da matriz micrítica primária em microespato, que aparece como cristais individualizados e bem visíveis de calcita (5 a $30 \mu \mathrm{m})$, é o processo mais tardio ocorrido durante a eodiagênese das rochas carbonáticas (Figura 8E). O neomorfismo é interpretado como resultante do aumento da pressão confinante, à medida que se processava o soterramento dos calcilutitos.
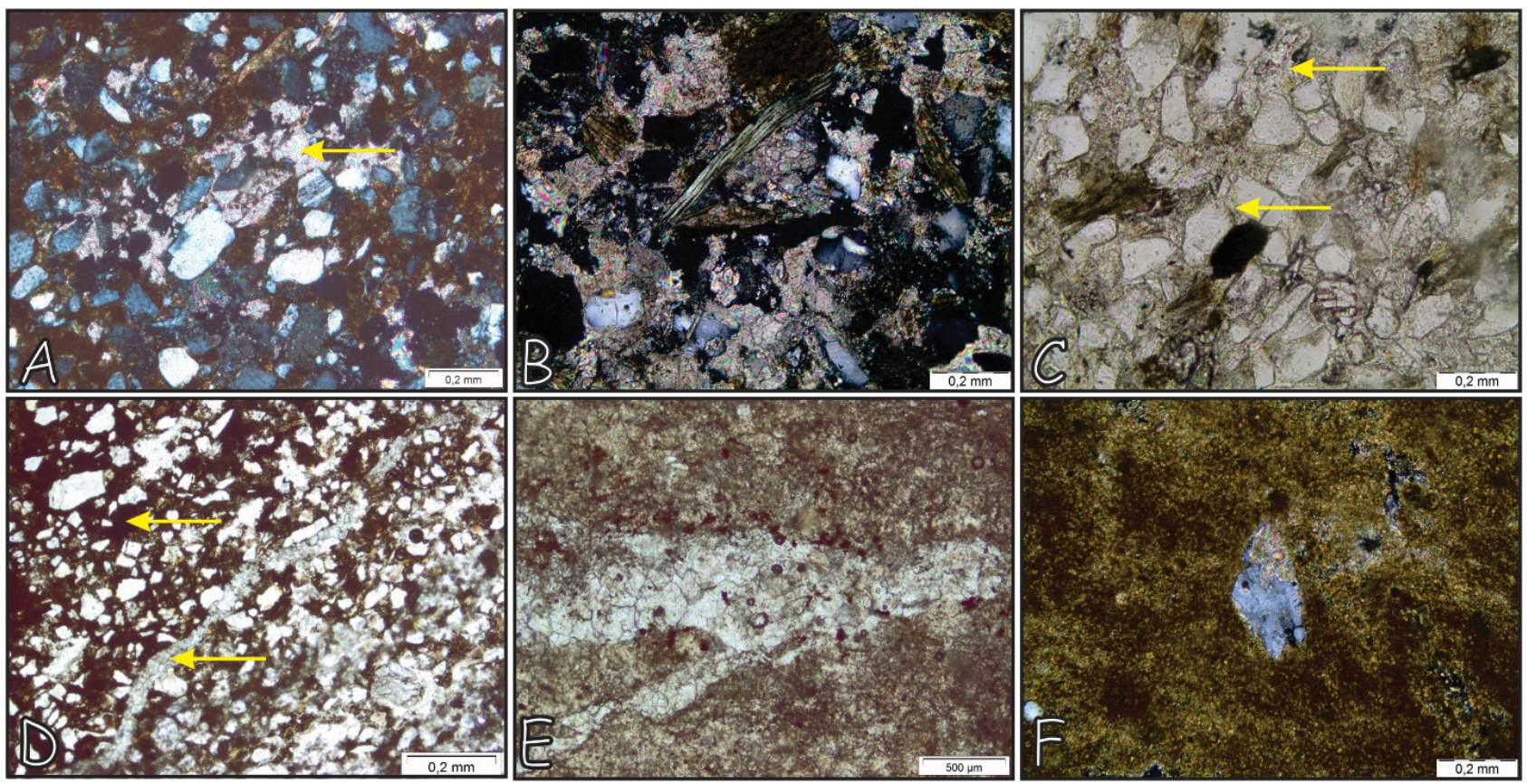

Figura 8. Principais feições diagenéticas características às rochas siliciclásticas e carbonáticas do Membro Crato. (A) Cimentação calcítica eodiagenética precoce indicada por seta amarela (nicóis cruzados). (B) Formação de pseudomatriz (mica amassada no centro da fotomicrografia) em estágio mais avançado da eodiagênese (nicóis cruzados). (C) Setas amarelas indicam cimento em menisco (nicóis paralelos). (D) Cimentação ferruginosa telodiagenética envolvendo grãos de quartzo (seta amarela superior) e calcita telodiagenética em microfraturas (seta amarela inferior) (nicóis paralelos). (E) Cristais microesparíticos de calcita (eodiagênese) truncados por veios de cristais espáticos de calcita (nicóis paralelos). (F) Cristal de gipsita em meio à matriz margosa. 
Outros processos, como cimento em menisco (produto de cimentação orientado gravitacionalmente; Nichols, 2009) e microfalhamentos (atividade tectônica ou sobrecarga devida a fenômenos de fluxo de massa de encostas sobre sedimento ainda mole; Neumann, 1999), são todos interpretados como feições pós-deposicionais eodiagenéticas, porém anteriores à recristalização da matriz (Figura $8 \mathrm{C}$ e Tabela 2).

Nas rochas arenáceas, os primeiros registros da eodiagênese são de bioturbações verticais (tubos) logo abaixo da superfície deposicional. Em seguida, a eodiagênese seria marcada por cimentação calcítica precoce (poroenvolvente) como registro da interação com as águas bacinais (Figura 8A). Uma incerteza, porém, fica por conta da presença de cimento gipsítico em alguns poros dos arenitos (Figuras 7F e 8F). A cimentação gipsítica é interpretada como nucleação eodiagenética de cristais de $\mathrm{CaSO}_{4} \cdot \mathrm{nH}_{2} \mathrm{O}$, em águas da bacia próximas de seu ponto de saturação (Collinson e Thompson, 1982; Warren, 2006). Na fácies Am, a relação de contato observada do cimento gipsítico com o poro (nucleado) e o cimento calcítico (adjacente e mais proeminente que ele) vistos em lâmina delgada sugere que sua formação pode ter antecedido a cimentação carbonática. Por fim, os estágios mais avançados de eodiagênese nos arenitos são marcados pela formação de pseudomatriz, rica em filossilicatos grossos, e formada às expensas da protomatriz transformada em estágios mais avançados de soterramento na bacia (Figura 8B e Tabela 2).

\section{Mesodiagênese}

Nas fácies Am e Scc, feições mesodiagenéticas típicas (por exemplo, contato suturado entre grãos, porosidade secundária do tipo honeycombed, desidratação de argilominerais etc.) não foram observadas na seção descrita para o Membro Crato. Dessa forma, por meio das características texturais e composicionais observadas tanto em macro como em microescala, pode-se inferir que o soterramento mesodiagenético dessas rochas na bacia não deve ter sido muito profundo (menos de $1.000 \mathrm{~m}$ ), a julgar tanto pela baixa compactação mecânica (poucos contatos entre grãos do arcabouço) como pelo baixo grau de transformação química (textura de protomatriz ainda reconhecível) observados nas rochas arenáceas. A mesma ideia é compartilhada por Silva (1988), que se baseou no estudo petrográfico das camadas evaporíticas. Também evidências de porosidade primária na matriz (protomatriz) e a existência de vazios preenchidos apenas parcialmente - e por cimento - corroboram a ideia de baixa compactação mecânica dessas rochas. Nesse âmbito, no caso dos calcilutitos (fácies $\mathrm{Cl}$ ), o argumento mais favorável para sua silicificação seria a presença de fluidos aquecidos em níveis rasos (eodiagenéticos), isto é, hidrotermalismo sensu stricto (Phillips, 2009). Na Bacia do Araripe, indícios de hidrotermalismo no Membro Crato têm sido descritos por Martill et al. (2008).

\section{Telodiagênese}

Indícios de telodiagênese na Bacia do Araripe são normalmente correlacionados a eventos de laterização amplamente reconhecidos nas bacias nordestinas e interpretados como produtos de mudança climática em condições próximas e/ou após a exumação (backstripping) cenozoica das unidades afetadas (Assine, 2007; Marques et al., 2014) (Tabela 2). Da mesma forma, a impregnação de cimento ferruginoso (laterização incipiente) nos depósitos das fácies $\mathrm{Cl}$ e Am teria ocorrido sob clima quente e úmido após sua exumação ou em condições quase superficiais (Figura 8D). No caso da fácies Am, o preenchimento de poro de microfraturas por cimento calcítico também é interpretado como telodiagenético (Figura 8D). Localmente, os vazios deixados pelas conchas de gastrópodes na fácies Scc também são interpretados como produto da dissolução carbonática sob condições telodiagenéticas.

\section{Considerações estratigráficas}

De acordo com Neumann (1999), a deposição carbonática e terrígena do Membro Crato (Formação Santana) inicia-se com pulsos transgressivos sobre as unidades fluviais subjacentes

Tabela 2. Resumo dos principais eventos diagenéticos observados na seção analisada no Membro Crato. Note a omissão da mesodiagênese, pois, como mencionado nos subtópicos anteriores, não foram encontradas feições mesodiagenéticas típicas.

\begin{tabular}{lcc}
\hline \multicolumn{1}{c}{ Estágios Processos } & Eodiagênese & Teolodiagênese \\
\hline Formação de fenestras (Cl) & $X$ & \\
Aglomerados de sulfetos (Am e Cl) & $\times$ & $X$ \\
Neomorfismo (Cl) & $X$ \\
Bioturbação (Am) & $X$ \\
Cimentação carbonática (Am e Scc) & $X$ \\
Compactação mecânica incipiente (Am) & $\times$ \\
Concreções carbonáticas (Lm) & $X$ & $\times$ \\
Microfalhamentos (Cl) & & \\
Cimento em menisco (Cl) & & \\
Laterização (Cl, Am, Scc) &
\end{tabular}


(Formação Barbalha) e finaliza com o desenvolvimento de uma superfície de descontinuidade local, sob a qual se depositaram os evaporitos das Camadas Ipubi. Dessa forma e por falta de discordância de caráter regional entre as Formações Barbalha e Santana, Neumann (1999) interpretou uma passagem transicional entre essas unidades, com retrogradação da primeira. Assim, o mesmo autor atribuiu os arenitos da Formação Santana (no Membro Crato) a uma extensão deltaica da coexistente Formação Barbalha no intervalo de tempo considerado (Neoaptiano). Sobre as Camadas Ipubi, Silva (1988) interpretou uma discordância erosiva de menor expressão (diastema) marcada por um nível conglomerático, que seria oriundo de fluxos gravitacionais de terras relativamente mais altas nas bordas das pequenas bacias evaporíticas. Assine (2007) usou do mesmo argumento ao agrupar as duas formações citadas na mesma sequência deposicional.

No presente estudo, algumas características estratigráficas da área estudada permitem interpretar a contemporaneidade do Membro Crato (Formação Santana) com a sotoposta Formação Barbalha. Entre essas características, destacam-se as seguintes: i) contatos verticais entre as fácies do Membro Crato são frequentemente gradacionais; ii) intervalos estratigráfica e paleontologicamente (Saraiva et al., 2013) semelhantes a depósitos do topo da Formação Barbalha (principalmente as fácies terrígenas Am e Scc); iii) intercalações verticais de calcilutitos laminados (tipicamente do Membro Crato) com as fácies Am e Scc; iv) similaridade entre o rumo de paleocorrentes obtidas na literatura para a Formação Barbalha (por exemplo, Assine, 1994) com o estimado no estudo para o Membro Crato. Com base no exposto, interpreta-se a inexistência de discordâncias significantes (regionais) entre as formações Santana e Barbalha, de modo que as unidades seriam contemporâneas, com empilhamento vertical explicado por retrogradação, ao menos até o topo do Membro Crato, na transição Aptiano-Albiano da bacia do Araripe. A mesma ideia é compartilhada por Neumann (1999) e Scherer et al. (2015).

\section{CONCLUSÕES}

Na seção analisada em Nova Olinda (CE), o Membro Crato registra deposição de sedimentos finamente laminados (fácies $\mathrm{Lm} \mathrm{e} \mathrm{Cl}$ ) com interdigitações laterais dentro de um sistema interpretado como lacustre. Contudo, é possível que tenha havido mudanças nas condições físico-químicas do lago e na razão entre o aporte sedimentar e o espaço para acomodação (A/E). A fácies Lm marca o período de maior expansão lacustre, enquanto as fácies $\mathrm{Cl}$ e Ec registram parcialmente as condições de maior aridez do lago. $\mathrm{O}$ desenvolvimento das fácies Am e Scc está relacionado a períodos de maior aporte sedimentar, com sedimentos oriundos de áreas-fonte relativamente próximas à bacia lacustre. As rochas sedimentares que compõem essas duas fácies teriam sido formadas a partir de leques aluviais existentes nas vizinhanças do sistema lacustre.

A análise petrográfica das rochas carbonáticas e siliciclásticas indica que a diagênese no intervalo de tempo considerado envolveu pouca transformação durante o soterramento, com indícios texturais e mineralógicos restritos àqueles eodiagenéticos e telodiagenéticos. Nas rochas siliciclásticas, a eodiagênese é marcada pela presença de bioturbações, formação de sulfetos sob condições de anoxia, cimentação carbonática e compactação mecânica incipiente, enquanto nas rochas carbonáticas essa fase diagenética é marcada pela formação de fenestras, cimento sulfetado, neomorfismo, cimento em menisco e microfalhamentos. Os fenômenos telodiagenéticos seriam todos relacionados à exumação tectônica da Bacia do Araripe durante o Cenozoico, marcados por intensa cimentação em óxi-hidróxidos de ferro, bem como à dissolução e à reprecipitação de calcita em fraturas. Os resultados sugerem que a sedimentação do Membro Crato foi ao menos parcialmente sincrônica com os depósitos terrígenos do topo da Formação Barbalha.

\section{AGRADECIMENTOS}

Os autores agradecem, especialmente, ao professor Wellington Ferreira da Silva Filho e ao geólogo Daniel Bezerra das Chagas os comentários e sugestões que ajudaram a melhorar este trabalho. Da mesma forma, os autores são gratos pelas contribuições dos dois revisores anônimos. Os autores agradecem, ainda, ao corpo editorial da revista o suporte à publicação e à professora Carla Bender Kotzian a ajuda na aproximação taxonômica ao nível de família dos contramoldes de gastrópodes.

\section{REFERÊNCIAS}

Allen, J. R. L. (1973). A classification of climbing ripple cross lamination. Journal of the Geological Society, 129, 537-541.

Allen, P. A., Allen, J. R. (2006). Basin analysis: principles and applications. Oxford: Blackwell Science.

Alling, H. L. (1945). Use of microlithologies as illustrated by some New York sedimentary rocks. Bull. Geological Society of America, 56, 737-756.

Anderton, R. (1985). Clastic facies models and facies analysis. In: P. J. Brenchley, B. P. J. Williams (Eds.), Recent developments and applied aspects, 31-47. Oxford: Blackwell Scientific.

Andresen, A., Bjerrum, L. (1967). Slides in subaqueous slopes in loose sand and silt. In: A. F. Richards (Ed.), Marine geotechnique, 221-229. University of Illinois Press. 
Assine, M. L. (1992). Análise estratigráfica da Bacia do Araripe, Nordeste do Brasil. Revista Brasileira de Geociencias, 22(3), 289-300.

Assine, M. L. (1994). Paleocorrentes e paleogeografia na Bacia do Araripe, Nordeste do Brasil. Revista Brasileira de Geociências, São Paulo, 24(4), 1-10.

Assine, M. L. (2007). Bacia do Araripe. Boletim de Geociências da Petrobrás, 15(2), 371-389.

Bates, C. C. (1953). Rational theory of delta formation. Bulletin American Association of Petroleum Geologists, 37, 2119-2162.

Blair, T. C., McPherson, J. G. (1994). Alluvial fans and their natural distinction from rivers based on morphology, hydraulic processes, sedimentary processes, and facies assemblages. Journal of Sedimentary Research, 64(3A), 450-489.

Boggs, J. S. (2009). Petrology of sedimentary rocks (2nd ed.). Cambridge: Cambridge University Press. http://dx.doi. org/10.1017/CBO9780511626487.

Brasil. Ministério de Minas e Energia. Departamento Nacional de Produção Mineral. (2014). Sumário mineral 2014, 152 p. Brasília. Acesso em: 01 de junho de 2015, <http://www. dnpm.gov.br/dnpm/sumarios/sumario-mineral-2014>.

Bustillo, M. A. (2010). Silicification of continental carbonates. In: A. M.Alonso-Zarza, L. H. Tanner (Eds.), Carbonates in continental settings: processes, facies and applications, $\mathrm{v}$. 62, 153-174. Amsterdam: Elsevier.

Carvalho, I. S., Bertini, R. J. (1999). Mariliasuchus: um novo Crocodylomorpha (Notosuchia) do Cretáceo da Bacia Bauru, Brasil. Revista Geologia Colombiana, 24, 83-105.

Castro, J. C., Valença, L. M. M., Neumann, V. H. (2006). Ciclos e sequencias deposicionais das Formações Rio da Batateira e Santana (Andar Alagoas), Bacia do Araripe, Brasil. Geociências, 25, 289-296.

Chagas, D. B., Assine, M. L., Freitas, F. I. (2007). Fácies sedimentares e ambientes deposicionais da Formação Barbalha no Vale do Cariri, Bacia do Araripe, Nordeste do Brasil. Geociências, 26(4), 313-322.

Choquette, P. W., Pray, L. C. (1970). Geologic nomenclature and classification of porosity in carbonates. AAPG Bulletin, 54(2), 107-250.

Collinson, J. D., Thompson, D. B. (1982). Sedimentary structures, 194 p. London: George Allen and Unwin.

Costa, A. B. S., Córdoba, V. C., Jardim de Sá, E. M., Scherer, C. M. S. (2014). Diagênese dos arenitos da Tectonossequência Rifte na Bacia do Araripe, NE do Brasil. Brazilian Journal of Geology, 44, 457-470.
Dickinson, W. R. (1970). Interpreting detrital modes of graywacke and arkose. Journal of Sedimentary Petrology, 40, 695-707.

Dott Junior, R. H. (1964). Wacke, greywacke and matrix; what approach to immature sandstone classification? Journal of Sedimentary Research, 34, 625-632.

Dunham, R. J. (1962). Classification of carbonate rocks according to depositional texture. In: W. E. Hamm (Ed.), Classification of carbonate rocks: a symposium, 108-121. American Association of Petroleum Geologists.

Fara, E., Saraiva, A. A. F., Campos, D. A., Moreira, J. K. R., Siebra, D. C., Kellner, A. W. A. (2005). Controlled excavation in the Romualdo Member of the Santana Formation (Early Cretaceous, Araripe Basin, northeastern Brazil). stratigraphic, palaeoenvironmental and palaeoecological implications. Palaeogeography, Palaeoclimatology, Palaeoecology, 218, 145-160.

Folk, R. L. (1962). Spectral subdivision of limestone types. In: W. E. Ham (Ed.), Classification of carbonate rocks: a symposium. v. 1, 62-84. American Association Petroleum Geologists Memoir.

Folk, R. L. (1968). Petrology of sedimentary rocks, $170 \mathrm{p}$. Austin: Hemphill Publishing.

Folk, R. L. (1974). Petrology of sedimentary rocks (2nd ed.), 184 p. Austin: Hemphill Publishing.

Freitas, A. B. L. P. (2010). Análise estratigráfica do intervalo siliciclástico aptiano da Bacia do Araripe (Formação Rio da Batateira). Dissertação (Mestrado). Rio de Janeiro: UFRJ.

Griffiths, J. C. (1967). Scientific method in the analysis of sediments, 508 p. EUA: McGraw-Hill Education.

Logan, B. W., Harding, J. L., Ahr, W. M., Williams, J. D., Snead, R. G. (1969). Late quaternary carbonate sediments of Yucatán Shelf, Mexico. In: B. W. Logan, M. N. Bass, D. E. Cebulski (Eds.), Carbonate sediments and reefs, Yucatán Shelf, Mexico, 5-128.

Mabesoone, J. M., Tinoco, L. M. (1973). Paleoecology of Aptian Santana Formation (Northeastern Brazil). Palaeogeogrophy, Palaeoclimatology. Paleaeocology, 14(2), 87-118.

Marques, F. O., Nogueira, F. C. C., Bezerra, F. H. R., Castro, D. L. (2014). The Araripe Basin in NE, Brazil: an intracontinental graben inverted to a high-standing horst. Tectonophysics, 630, 251-264.

Martill, D. M., Loveridge, R. F., Heimhofer, U. (2008). Dolomite pipes in the Crato Formation fossil lagerstätte (Lower Cretaceous, Aptian), of northeastern Brazil. Cretaceous Research, 29, 78-86.

Martill, D. M., Loveridge, R., Heimhofer, U. (2007). Halite pseudomorphs in the Crato Formation (Early Cretaceous, 
Late Aptian-Early Albian), Araripe Basin, northeast Brazil: further evidence for hypersalinity. Cretaceous Research, 28(4), 613-620.

Matos, R. M. D. (1992). The Northeast Brazilian rift system. Tectonics, 11(4), 766-791.

Moon, C. F., Hurst, C. W. (1984). Fabric of mud and shales: an overview. In: D. A. V. Stow, D. J. W. Piper (Eds.), Fine grained sediments: deep water processes and facies, v. 15, 579-594. Oxford: Blackwell Scientific Publications.

Moore, D. G., Scruton, P. C. (1957). Minor internal structures of some recent unconsolidated sediments. Bulletin-American Association of Petroleum Geologists, 41, 2723-2751.

Neumann, V. H. M. L. (1999). Estratigrafía, sedimentologia, geoquimica y diagénesis de los sistemas lacustres AptiensesAlbienses de la Cuenca de Araripe (Noreste de Brasil). Tesis (Doctorado). Barcelona: Universidad de Barcelona.

Nichols, G. (2009). Sedimentology and stratigraphy (2nd ed.), 419 p. Hoboken: Wiley-Blackwell.

Pettijohn, F. J., Potter, P. E., Siever, R. (1987). Sand and sandstone (3rd ed.), 618 p. Berlim: Springer Verlag.

Phillips, O. M. (2009). Geological fluid dynamics: subsurface flow and reactions, 299 p. Cambridge: Cambridge University Press.

Ponte, F. C., Hashimoto, A. T., Dino, R. (1991). Geologia das bacias mesozóicas do interior do Nordeste do Brasil. (Relatório Interno). Rio de Janeiro: Petrobrás/CENPES/ DIVEX/SEBIPE.

Ponte, F. C., Medeiros, R. A., Ponte-Filho, F. C. (1997). Análise estratigráfica da Bacia do Araripe: parte I: análise de sequências. II Simpósio da Bacia do Araripe e Bacias Interiores do Nordeste. Crato Atas: DNPM.

Ponte, F. C., Ponte-Filho, F. C. (1996). Estrutura geológica e evolução tectônica da Bacia do Araripe, 68 p. Recife: DNPM/DMME.

Regali, M. S. P., Viana, C. F. (1989). Sedimentos do Neojurássico-Eocretáceo do Brasil: idade e correlação com a escala internacional, 95p. Rio de Janeiro: Petrobrás.

Saraiva, A. A. F., Lima, F. J., Bantim, R. A. M., Barros, O. A. (2013). Guia para trabalhos de campo em paleontologia na Bacia do Araripe (2a ed.), 112 p. Crato: INAPAS.
Scherer, C. M. S., Goldberg, K., Bardola, T. (2015). Facies architecture and sequence stratigraphy of an early post-rift fluvial succession, Aptian Barbalha Formation, Araripe Basin, northeastern Brazil. Sedimentary Geology, 322, 43-62.

Schmidt, V., McDonald, D. A., Platt, R. L. (1977). Pore geometry and reservoir aspects of secondary porosity in sandstones. Bulletin of Canadian Petroleum Geology, 25(2), 271-290.

Selley, R. C. (1970). Ancient sedimentary environments, 237 p. London: Chapman \& Hall.

Silva, M. A. M. (1986). Lower Cretaceous sedimentary sequences in the Araripe Basin, Northeastern Brazil: a revision. Revista Brasileira de Geociencias, 16(3), 311-319.

Silva, M. A. M. (1988). Evaporitos do Cretáceo da Bacia do Araripe: ambientes de deposição e história diagenética. Boletim de Geociências da Petrobras, 2(1), 53-63.

Strong, E. E., Gargominy, O., Ponder, W. F., Bouchet, P. (2008). Global diversity of gastropods (Gastropoda; Mollusca) in freshwater. Hydrobiologia, 595, 149-166.

Troschel, F. H. (1857). Beobachtungen über die Fische in den Eisennieren des Saarbrücker Steinkohlengebirges. Verhandlungen des naturhistorischen Vereines der preussischen Rheinlande und Westphalens, 14, 1-19.

Tucker, M. E., Bathurst, R. G. C. (1990). Carbonate diagenesis, 312 p. Oxford: Alden Press.

Walker, R. G. (1992). Facies, facies models and modern stratigraphic concepts. In: R. G. Walker, N. P. James (Eds.), facies models: responses to sea level change, 1-14. Canadá: Geological Association of Canada.

Warren, J. (2000). Dolomite: occurrence, evolution and economically important associations. Earth-Science Reviews, $52,1-81$.

Warren, J. K. (2006). Evaporites: sediments, resources and hydrocarbons, 1041 p. New York: Springer Berlin-Heildelberg.

Weltje, G. J., von Eynatten, H. (2004). Quantitative provenance analysis of sediments: review and outlook. Sedimentary Geology, 171, 1-11.

Wilson, J. L. (1975). Carbonate facies in geologic history. New York: Springer-Verlag. 